Research Article

\title{
Experimental Research on Coal and Gas Delay Outburst and AE Characteristics under Conditions of Geostress and Gas Pressure Disturbance
}

\author{
Geng Jiabo, ${ }^{1,2}$ Liu Jiangtong, ${ }^{1}$ Li Xiaoshuang $\mathbb{D}^{1,2,3,4}$ Nie Wen, ${ }^{1}$ Zhang Dongming, \\ and Xu Jiang ${ }^{5}$ \\ ${ }^{1}$ School of Resources and Environmental Engineering, Jiangxi University of Science and Technology, Ganzhou 341000, China \\ ${ }^{2}$ State Key Laboratory of Safety and Health for Metal Mines, Sinosteel Maanshan General Institute of Mining Research Co., Ltd., \\ Maanshan 243000, China \\ ${ }^{3}$ School of Civil Engineering, Shaoxing University, Shaoxing 312000, China \\ ${ }^{4}$ College of Civil Engineering, Qilu Institute of Technology, Jinan 250200, China \\ ${ }^{5}$ State Key Laboratory of Coal Mine Disaster Dynamics and Control, Chongqing University, Chongqing 400044, China
}

Correspondence should be addressed to Li Xiaoshuang; xsli2011@126.com

Received 24 June 2021; Accepted 12 August 2021; Published 25 August 2021

Academic Editor: Song Jiang

Copyright (c) 2021 Geng Jiabo et al. This is an open access article distributed under the Creative Commons Attribution License, which permits unrestricted use, distribution, and reproduction in any medium, provided the original work is properly cited.

\begin{abstract}
Adopting yellow mud as barrier layer materials, coal and gas delay outburst experiments under conditions of geostress and gas accumulation disturbance were carried out by using self-developed simulation system, to find out roles of geostress and gas pressure played in the process of the delay outburst and ways to predict it, through analysis of variations of gas pressure, and $\mathrm{AE}$ characteristics during the process. The results show that after the geostress increased by $0.11 \mathrm{MPa}$ from $1.80 \mathrm{MPa}$, an outburst occurs, while in gas accumulation situations, the gas pressure increase of $0.27 \mathrm{MPa}$ from $0.67 \mathrm{MPa}$ induces an outburst; hence, geostress is one of the dominant factors impacting an outburst occurrence. The lasting time of the outburst triggering under geostress disturbance is shorter than that under gas accumulation disturbance, while the duration of the outburst development under gas accumulation conditions is longer than that under geostress conditions. Coal seam breakage by geostress is the precondition for an outburst risk, and gas expansion energy is the dominant parameter influencing the duration of the outburst development. The AE signals show distinctive features in different stages of the outburst under geostress disturbance. At the preparation stage of the outburst, the AE signals increase sharply but have a low intensity and then drop to a lower balance level. At the triggering stage, the AE signals become active and increasing until up to the peak where the outburst occurs, and the intensity is highest.
\end{abstract}

\section{Introduction}

The coal and gas delay outburst (hereinafter referred to as the delay outburst) is considered as one of the main patterns of the dynamic disaster, the coal and gas outburst. It is an outburst accident that does not occur during blasting or extracting operations, but takes place sometime after the operations at the blasting or working site. Bearing the characteristics of time delay and imperceptibility, the delay outburst poses a serious risk to coal mine safety [1-3].
Sufficient achievements have been made in the study of instantaneous outbursts [4-6], while positive research results on delay outbursts are relatively few up to now. In the 1950s, Hodote, an expert from the former Soviet Union, found the phenomenon of the delay outburst and analyzed the reason from the duration of the blasting breakage propagating from the blasting source to the deep coal seam. According to the actual situation, Jiang and Guo [7] analyzed various reasons for the delayed outburst and carried out a simulation test for the delayed outburst according to the analysis results. Some researchers $[8,9]$ 
discussed the reasons for the delay outburst in terms of the coal bearing capacity decreasing with time and the poor gas diffusion capacity in the pressure relief zone of the coal seam. Bao [10] analyzed a large number of in situ cases and found that the majority of delay outburst accidents occur after the increasing damage or even rupture of the pressure relief zone, as well as in the circumstances of engineering disturbances at the blasting or mining sites. Several scholars investigated the mechanism of the delay outburst through physical simulation experiments. $\mathrm{Xu}$ et al. [11] and Li et al. [12] conducted physical simulation experiments with different materials as the barrier layer and believed that the delay outburst results from either the creep deformation of the hard coal barrier layer or the decreasing of the supporting force in the pressure relief zone.

On the other hand, due to the influence of geostress and gas pressure during the outburst process, crack initiation and development behaviors inside the coal rocks produce the acoustic emission (AE) phenomenon. As a result, $\mathrm{AE}$ monitoring which is a research method for studying and predicting deformation and failure of materials is introduced into monitoring and forecasting coal and gas outburst incidents $[13,14]$. It is proved to be an effective method to analyze the mechanism of coal and gas outbursts.

Efforts on delay outburst mechanism are mainly focused on several aspects. The bearing force of coal rock masses decreases with time under the action of geostress. The role of gas played in the delay outburst remains unclear and few physical simulations discuss the variation rules of gas pressure, temperature, and $\mathrm{AE}$ characteristics during the entire delay outburst process whereas these parameters are indispensable to understanding the mechanism and prediction of delay outburst risks. Using yellow mud as the barrier materials, delay outbursts caused by geostress disturbance and gas accumulation in front of the working face are separately simulated in this work. The influences of geostress and gas pressure on delay outbursts and evolution rules of the above-mentioned parameters during the delay outburst process are also discussed.

\section{Experiment Method}

2.1. Experiment Equipment. Self-developed large-scale coal and gas outburst simulation platform was used to simulate the delay outbursts [15]. The temperature sensor and gas pressure sensor installed in the device can synchronously detect the variations of the temperature and gas pressure in the coal body, and gas pressure sensor is installed in the middle area inside the test box. When the temperature and gas pressure in the box change, the temperature sensor and gas pressure sensor will transmit the temperature and gas pressure change to the analysis equipment through digital signals and electrical signals for storage. Figure 1 shows the picture of the simulation system.

Additionally, the PCI-2 AE system produced by American Physical Acoustics Company (PAC) was selected to collect the AE signals in the process of coal and gas outbursts. The AE threshold value was set at $35 \mathrm{~dB}$, and two AE sensors were symmetrically arranged at the central part of the external board of the outburst chamber, as shown in Figure 2.

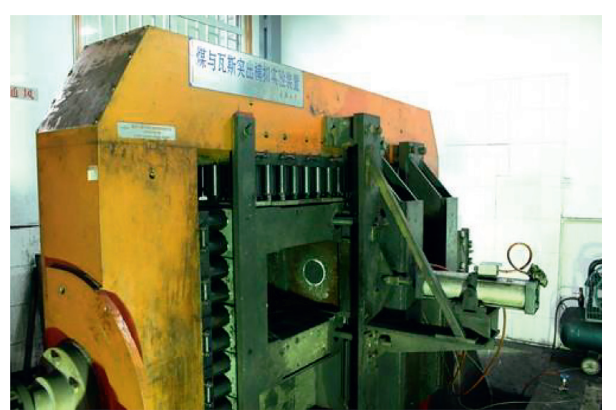

Figure 1: Picture of coal and gas outburst simulation system.

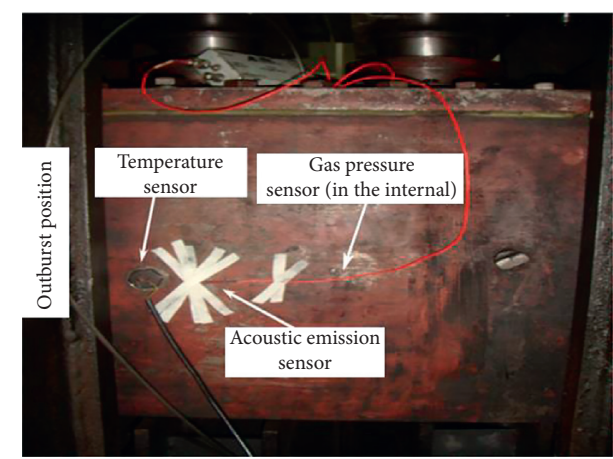

Figure 2: Layout of $\mathrm{AE}$ and temperature sensors.

2.2. Experiment Design. Through comprehensive analysis of coal and gas delay outburst cases, it is found [16] that the majority outbursts generally occur within 100 meters range of the outburst crater at which the stress concentration is caused by blasting or/and coal mining operations, and the gas emission increases sharply before in situ outburst occurrence. It can be seen that both the disturbances of geostress and the increase of gas pressure are likely to stimulate the delay outburst. To understand the influence of geostress disturbance and gas pressure increases on delay outbursts, simulation experiments for coal and gas delay outbursts under two different conditions including geostress disturbance and gas accumulation disturbance are designed separately, i.e., by increasing the $P 3$ after uncovering the baffle plate to simulate the delay outburst caused by in situ stress disturbance in the coal seam in front of the working face, and by increasing the gas pressure after the baffle plate opened to simulate the delay outburst caused by gas accumulation in the coal seam ahead of the work face.

In the experiments, a series of physical simulation tests are carried out against the background of coal seam occurrence conditions at $265 \mathrm{~m}$; the coal specimens were sampled from coal seam 9\# of Linhua Coal Mine, Guizhou Province, China. The moisture content of the specimens was constant at $4 \%$.

Referring to China's empirical formula [17] for geostress stress changing with buried depth, the vertical stress $(\sigma)$ of coal seam can be obtained as follows:

$$
\sigma=0.0208 H+2.195=7.7 \mathrm{MPa} .
$$

To calculate the geometric similarity constant $\left(C_{L}\right)$ and volume force similarity constant $\left(C_{\rho}\right)$, 


$$
\begin{aligned}
& \mathrm{CL}=\frac{L_{p}}{L_{m}}, \\
& C_{\rho}=\frac{\rho_{p}}{\rho_{m}},
\end{aligned}
$$

where $L_{p}$ is the prototype size, $\mathrm{m} ; L_{m}$ is model size, $\mathrm{m} ; \rho_{p}$ is the prototype density, $\mathrm{kg} / \mathrm{m}^{3}$; and $\rho_{m}$ is the model density, $\mathrm{kg} / \mathrm{m}^{3}$.

The stress similarity constant can be calculated as follows:

$$
C_{\sigma}=C_{L} * C_{\rho} .
$$

Gas pressure calculation [18] is as follows:

$$
Y=1 E-5 * H^{2}+0.0022 H+0.005,
$$

where $H$ is depth, $\mathrm{m}$, and $Y$ is the gas pressure, $\mathrm{MPa}$.

The original vertical stress $\sigma=4.0 \mathrm{MPa}$ and gas pressure $P=0.67 \mathrm{MPa}$ were calculated. According to the stress distribution law in front of the working face, the three indenters above the box are set to provide transverse principal stress, named $P 1 \sim P 3$, respectively. An indenter behind the box provides the axial principal stress, named $P 4$; and the pressure was constant at $4.00 \mathrm{MPa}$. The constant values of $P 1, P 2$ threshold $P 3$, and $P 4$ were $1.80 \mathrm{MPa}, 3.60 \mathrm{MPa}$, $1.80 \mathrm{MPa}$, and $2.40 \mathrm{MPa}$, respectively. The initial gas pressure was constant at $0.67 \mathrm{MPa}$. Vacuum extraction time was 2 hours and gas adsorption time was 24 hours.

2.3. Layout of Yellow Mud Barrier Layer. After the roadway excavation and coal mine extraction, the coal around the working face steps into a plastic state due to stress concentration. Wold et al. $[19,20]$ and some other researchers believed that the outburst is caused by plastic deformation and failure of the coal seam. Bao [10] analyzed in situ delay outburst cases and concluded that the delay outburst is the result of the development of coal seam plastic deformation under the action of external force.

In this study, hard-plastic yellow mud was selected to simulate the plastic coal seam near the outburst crater. The hard yellow mud has a certain strength that can bear some degree of stress changing inside the coal mass to prevent an outburst accident. Moreover, it can maintain in the plastic state under existing loading conditions and realistically simulate the plastic deformation and failure of the coal seam. The yellow mud was finely ground and mixed with water for being in a hard-plastic state; afterwards, it was filled into the coal and compacted. The layout of yellow mud in the chamber is shown in Figure 3. The cohesive force $\mathrm{C}$ of the compacted yellow mud was about $0.15 \mathrm{MPa}$, and the internal friction angle $\varphi$ was about $45^{\circ}$ [21-23].

The force applied to the yellow mud barrier layer in the coal chamber is shown in Figure 4(a) and is simplified as the shear force model in Figure 4(b) for calculation. There is a PVC plate with a radius of $50 \mathrm{~mm}$ bonded outside the outburst crater by silicone rubber; hence, it can provide an adhesive force $\left(F_{\mathrm{a}}\right)$ to prevent the outburst. Since the radius

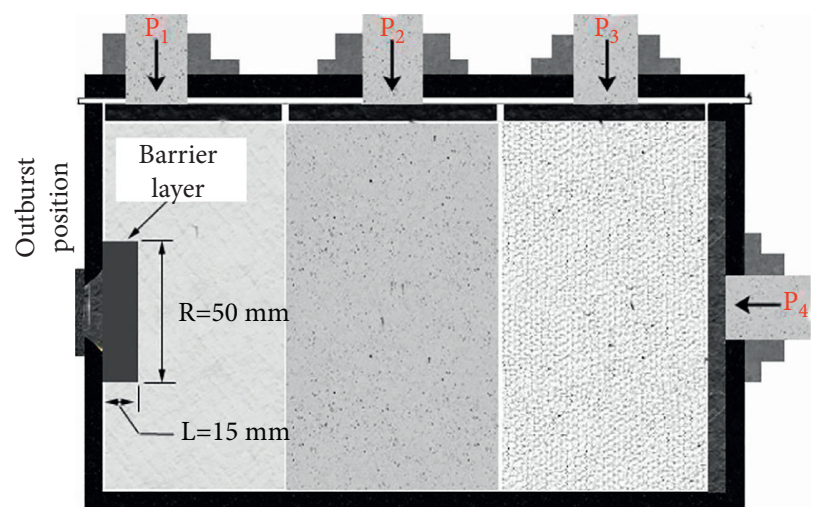

FIgURE 3: Stress distribution loaded on coal specimens and layout of yellow mud.

of the outburst crater $(r)$ is $30 \mathrm{~mm}$, the equivalent stress provided by the adhesive force $F_{\mathrm{a}}$ is represented by $\sigma_{\mathrm{e}}$. The adhesive force is taken as $0.4 \mathrm{MPa}$; hence, the value of $\sigma_{\mathrm{e}}$ is $0.71 \mathrm{MPa}$, i.e., $\sigma_{\mathrm{e}}=0.4 \times \pi \times\left(50^{2}-30^{2}\right) /\left(\pi \times 30^{2}\right)=0.71 \mathrm{MPa}$. $P$ is the gas pressure, taken as $0.7 \mathrm{MPa} ; \sigma_{1}$ is the normal stress of yellow mud transmitted by the coal mass, taken as $1.8 \mathrm{MPa} ; \sigma_{\mathrm{h}}$ is the shear force of yellow mud transmitted by the coal mass, taken as $2.4 \mathrm{MPa}$. The ultimate stress $(F)$ causing yellow mud deformation and failure can be calculated by the following equation:

$$
F=\left(\sigma_{h}+P-\sigma_{e}\right) \times \pi \times r^{2}=2 \times \pi \times r \times \tau \times L,
$$

where $\tau$ is the shear strength of yellow mud, derived by the equation, $\tau=C+\left(\sigma_{1}+P\right) \times \tan \varphi$, and $L$ is the thickness of yellow mud.

The simulation experiments were carried out for three times, and the actual gas pressure was $0.67 \mathrm{MPa}$. The instantaneous outburst occurred when the thickness of the yellow mud was $10 \mathrm{~mm}$, and delay outbursts took place when the thickness was $15 \mathrm{~mm}$. The two simulation experiments under the conditions of $15 \mathrm{~mm}$ thickness of the yellow mud were mainly discussed in this work.

\section{Delay Outburst Simulation Experiment}

3.1. Delay Outburst under Geostress Disturbance. Based on the description of the coal and gas outburst process in the literature [6] and combined with the screenshots of the outburst videos (Figure 5), the delay outburst process can be divided into four stages, including preparation, triggering, development, and termination stages, in which the term termination is defined as the end of coal ejection. Figure 6 shows the variation curve of the geostress vertically applied to the coal mass. The red point a in Figure 6 represents the moment where no outburst occurred after the baffle plate was opened. 42 seconds later after this opening, while $P 3$ was gradually increased to $1.91 \mathrm{MPa}$ from $1.80 \mathrm{MPa}$, the barrier materials began to break and were stepping into the outburst triggering stage. If the stress condition remained unchanged, the barrier layer constantly deformed and was destroyed until it encountered an outburst; afterwards it came to the outburst development stage. Figure 6 shows the 


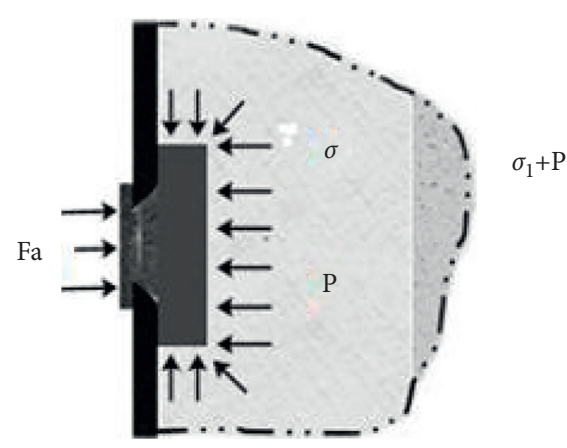

(a)

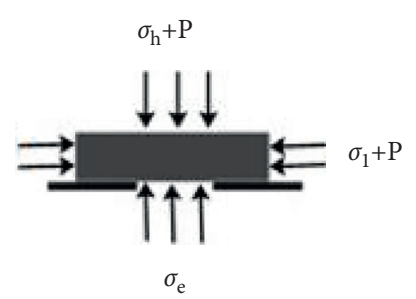

(b)

Figure 4: Bearing model of yellow mud barrier layer.
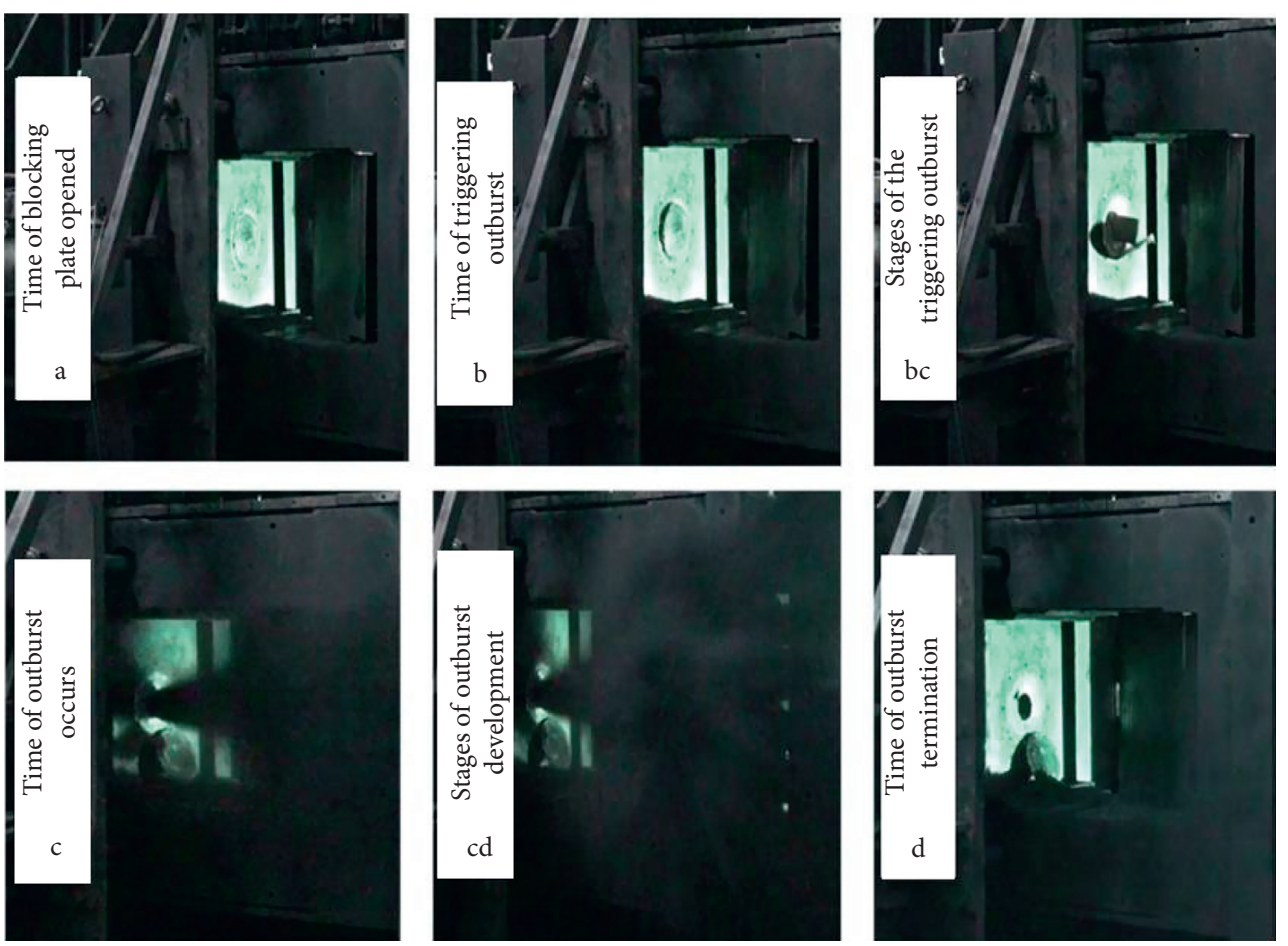

Figure 5: Video screenshots of the delay outburst caused by geostress disturbance.

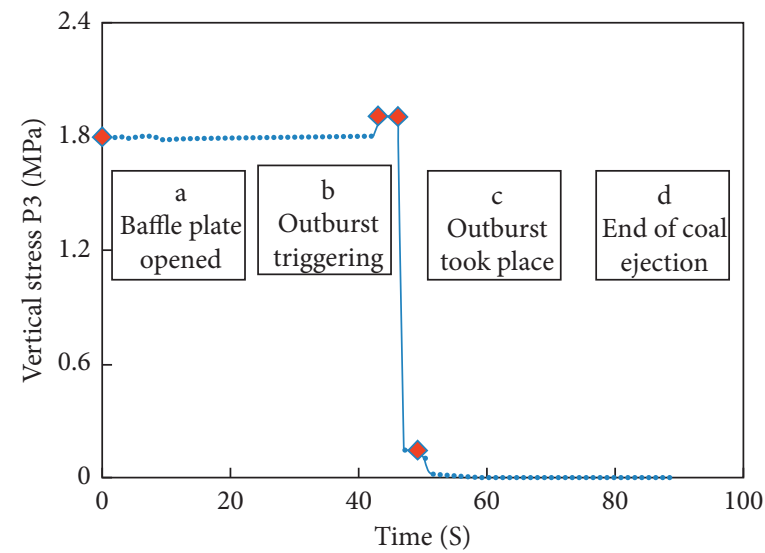

FIGURE 6: Variation curve of stresses loaded vertically. 


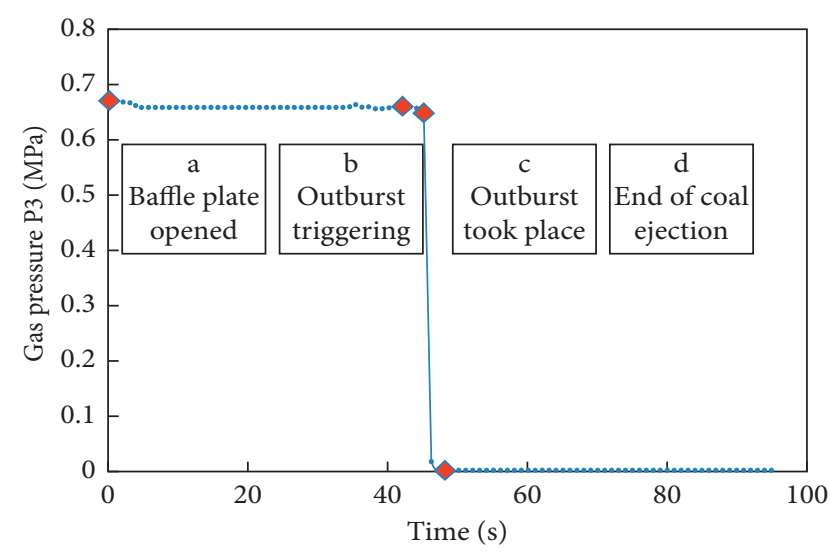

(a)

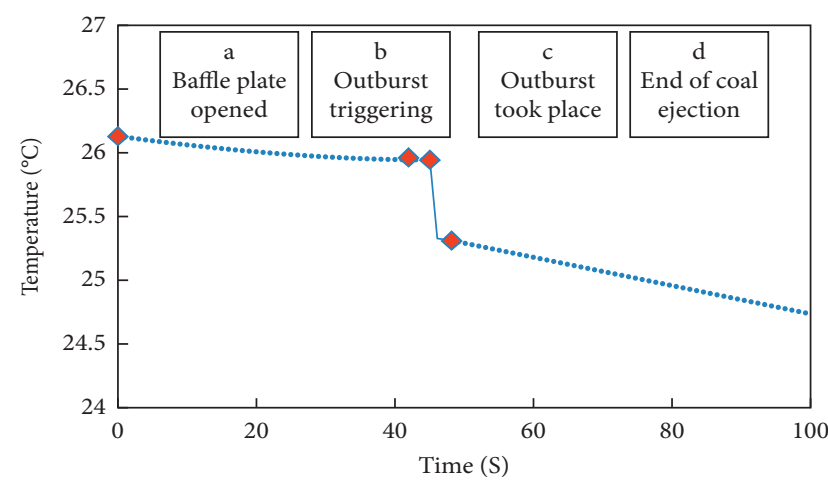

(b)

Figure 7: Gas pressure (a) and temperature (b) change curves during the delay outburst caused by geostress disturbance.

corresponding gas pressure and temperature evolution curves in the experiment, and Figure 7 provides the corresponding video screenshots at different outburst moments. The entire initiation process of the outburst is analyzed in terms of stages (Figures 5-7).

At the outburst preparation stage (Stage $a b$ ), when the baffle plate was quickly opened (moment a in Figures 5 and 7), equivalent to the completion of mining operations at the work face, the stress state of the coal seam was subjected to a change, the gas pressure only had a slight decrease, and the temperature declined slowly. However, no deformation or failure occurred in the barrier layer, and there were no signs of damage at the outburst crater. At this stage, the stresses inside the coal rocks were altered after the completion of mining activities; physical and mechanical properties, gas pressure, and other parameters of the coal seam were changed. Nevertheless, the coal and rock masses were still able to bear these changes and keep in a new balance state due to the presence of the barrier layer.

During the outburst triggering stage (Stage $b c$ ), namely, 42 seconds after the baffle plate was uncovered, the coal and rock masses were disturbed by geostress disturbance, namely, gradually increasing the $P 3$ loading by $0.11 \mathrm{MPa}$ (from 1.8 $\mathrm{MPa}$ to $1.91 \mathrm{MPa}$ ), corresponding to moment $b$ in Figures 5 and 7, the outburst hole was destructed, and the barrier layer materials were constantly ejected from the outburst chamber. During this period, the gas pressure and temperature decreased slowly. When the residual barrier materials were not enough to resist the coal failure and ejected out, an outburst occurred, corresponding to moment $c$ in Figures 5 and 7. In the triggering stage (Stage $b c$ ), due to the increase of vertical loading, the coal rock masses were further destroyed and the elastic potential energy largely increased. The energy inside the coal and rocks was sufficient to destroy the barrier layer and initiate an outburst, leading to the coal seam breakage and ejection. The triggering of the outburst produced an early outburst cavity, adsorbed gases in the coal seam had the behavior of desorption, and the gas pressure and temperature were also reduced accordingly. The triggering process lasted only 3 seconds.
At the outburst development stage (Stage $c d$ ), after the outburst took place, the accumulated energy was released instantaneously, and the broken coal and rocks were constantly destroyed and ejected out until the outburst terminated. During this stage, the gas pressure declined instantaneously, and the adsorbed gas continued to desorb and expand power rapidly. The temperature dropped significantly. The duration time of the development stage (Stage $c d$ ) was only 3 seconds.

3.2. Delay Outburst under the Disturbance of Gas Accumulation. In the same way combined with the gas pressure and temperature change curves during the delay outburst under gas accumulation conditions (Figure 8) and the outburst video screenshots (Figure 9), the delay outburst process under the disturbance of gas accumulation is discussed in stages.

At the outburst preparation stage (Stage $a b$ ), after opening the baffle plate (corresponding to moment a in Figures 8 and 9), the stress conditions of the coal and rocks became worse. As a result of the presence of the barrier layer, the stress state of coal rocks was able to reach a new balance. When the gas pressure was gradually improved by $0.27 \mathrm{MPa}$ from $0.67 \mathrm{MPa}$ to $0.94 \mathrm{MPa}$, the total energy inside the coal rocks soared to the threshold of triggering an outburst; subsequently, the outburst crater was deformed and an outburst was initiated (corresponding to moment $b$ in Figures 8 and 9). Stage $a b$ is equivalent to the period of stress changing in the coal seam after coal mining, during which gas accumulated ahead of the work face and energy accumulated in the coal seam.

At the outburst triggering stage (Stage $b c$ ), after the outburst took place, the elastic energy and gas expansion energy accumulated in the coal rock masses squeezed out the barrier materials, unstable coal particles were separated from solid coal, the bearing capacity of the barrier layer reduced drastically, and finally an outburst occurred (corresponding to moment $c$ in Figures 8 and 9). Stage $b c$ was the triggering stage of the outburst and lasted for 33 seconds, where the 


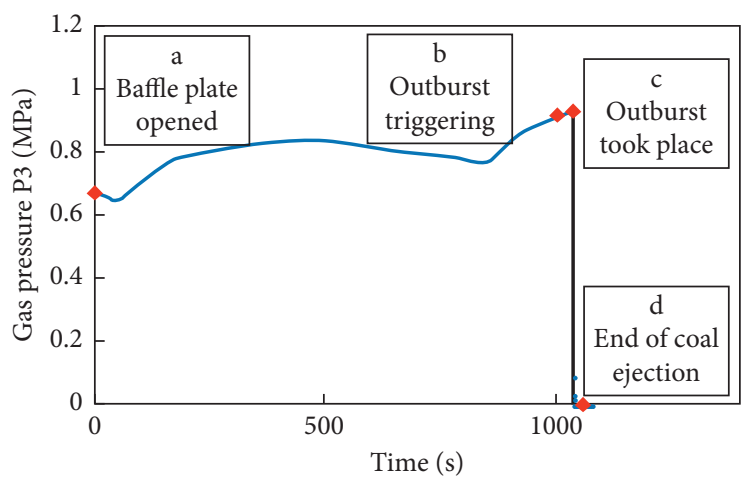

(a)

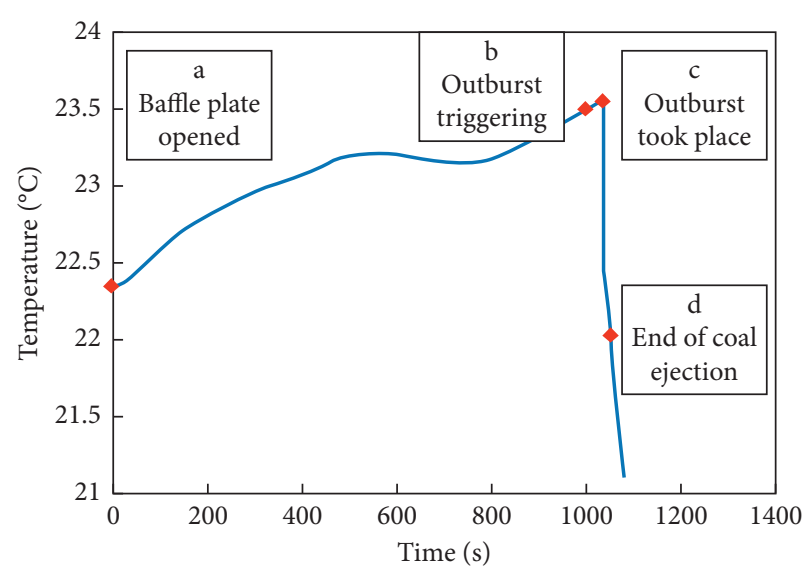

(b)

FIgURE 8: Gas pressure (a) and temperature (b) change curves during the delay outburst caused by gas accumulation ahead of the work face.
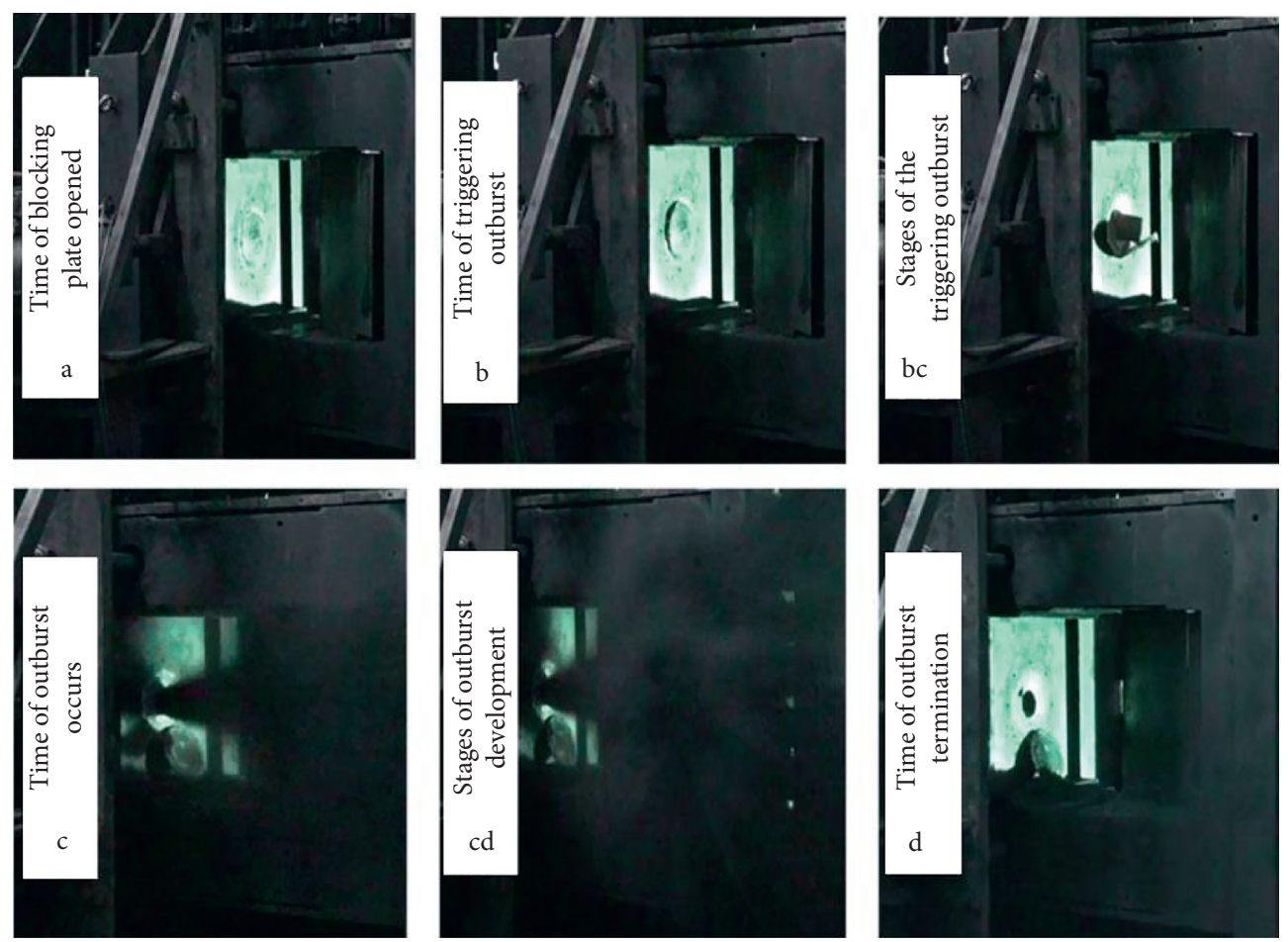

FiguRE 9: Video screenshots of the delay outburst caused by gas accumulation in front of the working face.

barrier layer was destroyed under the combined action of geostress and gas pressure.

In the process of outburst development (Stage $c d$ ), a large amount of pulverized coal was quickly ejected from the chamber, the gas pressure decreased instantly, the accumulated energy in the coal seam fractured the coal and ejected them out, the adsorbed gas continuously desorbed into the free state and constantly broke the coal masses, and the temperature also declined significantly. Here the development stage, $c d$, lasted for 21 seconds.

From Figures 7(b) and 8(b), it can be concluded that the change of coal temperature is consistent with the change of gas pressure, indicating that the gas in the coal seam is almost simultaneously desorbed in large quantities, resulting in the decrease of coal temperature during the outburst process.

\subsection{Comparison of Delay Outburst under Two Disturbance} Conditions. According to the video screenshots and comparison analysis of the results of the delay outburst simulation experiments under two disturbance conditions (Table 1), it can be concluded that the outburst takes place when the geostress gradually increases from $1.80 \mathrm{MPa}$ to 
TABle 1: Comparison of delay outburst under two disturbance conditions.

\begin{tabular}{|c|c|c|c|c|c|c|}
\hline Test types & $\begin{array}{l}\text { Parameter threshold } \\
\text { value }(\mathrm{MPa})\end{array}$ & $\begin{array}{l}\text { Increment } \\
(\mathrm{MPa})\end{array}$ & $\begin{array}{l}\text { Degree } \\
(\%)\end{array}$ & $\begin{array}{l}\text { Preparation time } \\
\text { (s) }\end{array}$ & $\begin{array}{l}\text { Triggering time } \\
\text { (s) }\end{array}$ & $\begin{array}{l}\text { Development time } \\
(\mathrm{s})\end{array}$ \\
\hline Geostress disturbance & 1.80 & 0.11 & 6.1 & 42 & 3 & 3 \\
\hline $\begin{array}{l}\text { Gas accumulation } \\
\text { disturbance }\end{array}$ & 0.67 & 0.27 & 38.6 & 1002 & 33 & 21 \\
\hline
\end{tabular}

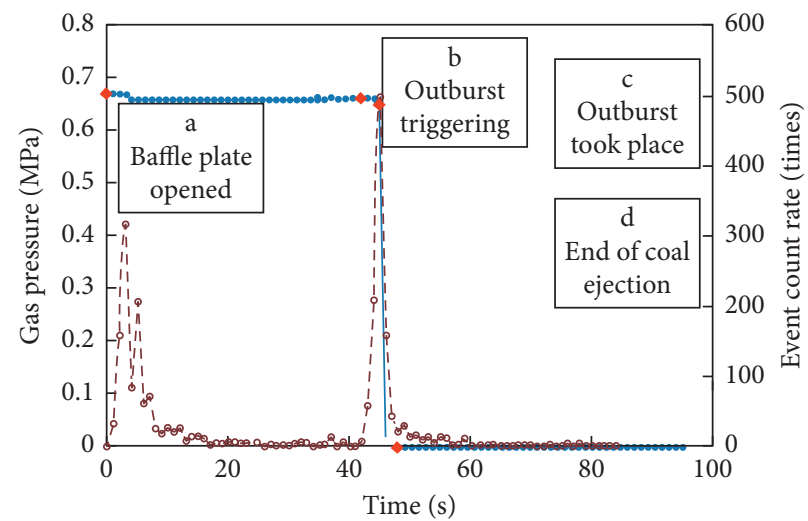

(a)

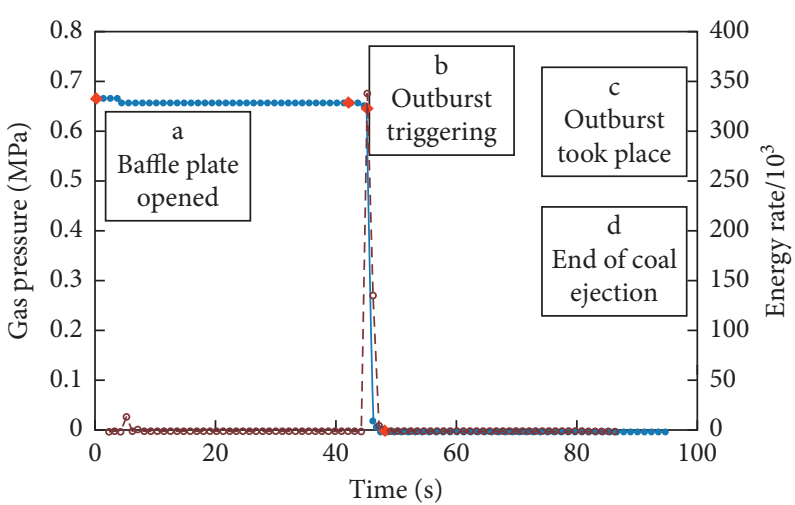

(b)

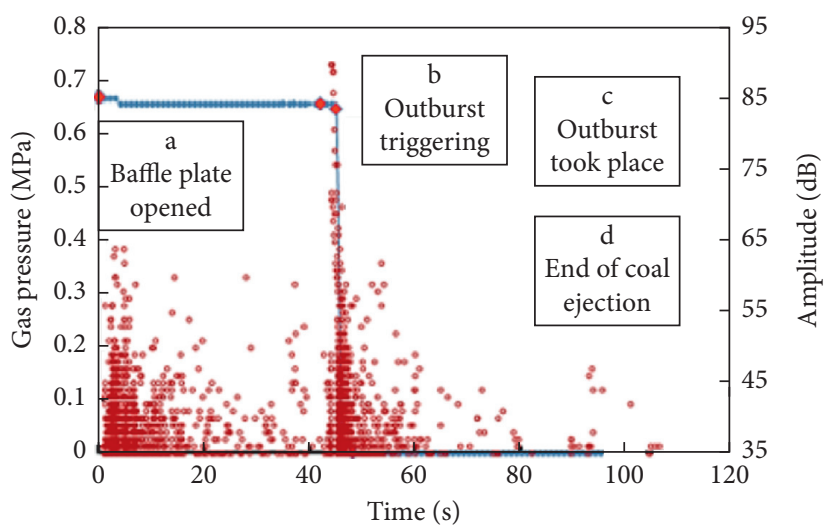

(c)

Figure 10: AE characteristics of the delay outburst under the geostress disturbance. (a) AE event count rate variation; (b) AE energy rate variation; (c) AE amplitude variation.

$1.91 \mathrm{MPa}$ (namely, an increase of 6.1 percent), but through gas accumulation, it needs to gradually increase 38.6 percent of the gas pressure from $0.67 \mathrm{MPa}$ to $0.27 \mathrm{MPa}$ to stimulate the occurrence of an outburst. This indicates that geostress disturbance is more likely to induce an outburst and geostress is the dominant factor affecting the initiation of an outburst since coal rock masses are constantly breaking with the increasing geostress. In addition, the preparation time of an outburst is associated with the disturbed conditions of the coal seam. Specifically, the geostress disturbance is mainly related to the coal seam loading pressure and engineering activities, while the gas accumulation disturbance is relevant to the gas accumulation velocity and seam gas release ability. When the stress disturbance is applied to the coal seam, the yellow mud barrier layer begins to deform and break. When the bearing force of the remaining barrier layer cannot maintain the original balance, an outburst occurs. The duration of the outburst development lasts only 3 seconds under the disturbance of geostress, while it lasts for 21 seconds under the disturbance of gas pressure. Therefore, it can be considered that gas expansion energy is the dominant factor affecting the outburst development. The failure of coal and rock masses by geostress is the precondition of an outburst. Gas expansion can promote the development of the outburst. The duration of ejecting pulverized coal can indirectly reflect the intensity of an outburst; thus, the outburst intensity caused by gas pressure disturbance is higher than that caused by geostress disturbance.

In terms of predicting a delay outburst, the triggering time of the outburst caused by gas accumulation is relatively longer (33 seconds), and the outburst is initiated more slowly. Moreover, gas accumulation ahead of the work face generally induces corresponding changes in the gas emission amount and coal seam temperature; hence, the warning 
signs are more obvious for an outburst under gas accumulation disturbance. The geostress disturbance causes high velocity of an outburst and the outburst is initiated more quickly. As a result, it is critical to strengthen the supporting of coal and rocks and adopt reasonable roof caving methods, as well as employ other means to in situ monitor coal seam changes for coal mine safety production.

\section{AE Characteristics}

As to $\mathrm{AE}$ parameters, this study selected the $\mathrm{AE}$ count rate reflecting the frequency of the $\mathrm{AE}$ events, the $\mathrm{AE}$ energy rate reflecting the change of the energy released in the AE events, and the $\mathrm{AE}$ amplitude reflecting the magnitude of the $\mathrm{AE}$ signals to investigate the $\mathrm{AE}$ characteristics in the process of the delay outburst under the condition of geostress disturbance, and the results are shown in Figure 10 [24, 25].

Further analysis of Figure 10 shows that after the blocking plate was opened, the stress state of the coal rocks at the outburst crater began to change. The coal and rock masses were deformed and damaged under the action of geotress and gas pressure, resulting in high $\mathrm{AE}$ events. Due to the restricting function of the barrier layer, broken coal and rocks would not immediately eject out, and the gas pressure slightly decreased. With the adjustment of the internal stress of the coal rocks reaching a new balance, the number of the AE events stabilized at a low level. Although the $\mathrm{AE}$ count rate was high after opening the baffle plate, the energy rate was relatively low. At the same time, the $\mathrm{AE}$ amplitude was basically at a low level. When the geostress disturbance was applied to the coal seam, original internal balance was destroyed, the stress was redistributed, and the coal and rock masses continued to fracture. The gas stored in the coal seam desorbed to a free state and continuously expanded. The rapid expansion of gas in the chamber further fractured the coal particles. At this stage, the $\mathrm{AE}$ count rate began to increase, but the AE energy and amplitude were still at a relatively low level. With the continuous coal damage and increase of free gas content, the barrier layer was unable to maintain the balance, finally resulting in an outburst occurrence. The accumulated energy of the coal rock masses was released instantly. Under the action of geostress and gas pressure, the coal and rock masses were continuously destructed and ejected out. When the $\mathrm{AE}$ count rate reached the maximum of 498 times per second, the AE energy and amplitude were up to the peak.

After the coal ejection terminated, the gas in the residual coal rock masses continued to desorb and expand, and the AE signals were still detected. Fractures and cracks still propagated in the coal seam at this time, but the energy was not enough to eject the broken coal and rocks. During this stage, the energy was rather low and the $\mathrm{AE}$ amplitude returned to a lower level with few $\mathrm{AE}$ events still generating.

During the entire process of the delay burst, the $\mathrm{AE}$ signals increased sharply and then decreased to a lower level when the blocking plate was opened. After the triggering of the outburst, the AE signals increased again and reached the peak value. Namely, if an outburst does not occur immediately after the completion of mining operations, a significant increase in AE signals after a certain stable period may indicate the arrival of an outburst. Therefore, AE monitoring can be used as a device to predict the coal and gas delay outburst.

\section{Conclusion}

(1) It is appropriate to divide the entire process of the coal and gas delay outburst into four stages, including preparation, triggering, development, and termination stages. Both the temperature and gas pressure decline under the two different disturbance conditions in the preparation stage. Due to different inducing mechanisms of the outbursts during the triggering stage, the gas pressure and temperature change rules show different features under the two different disturbances.

(2) The triggering and development time of the outburst caused by gas accumulation in the coal seam ahead of the work face are longer than those by geostress disturbance. Geostress and gas pressure play different roles in the process of the outburst. The coal seam destruction by geostress is the precondition for an outburst, and the gas expansion energy is the main dominant factor for the duration time of an outburst.

(3) According to the AE characteristics in the process of the coal and gas delay outburst, if the AE signals increase significantly from a lower level with no occurrence of an outburst after the completion of mining operations, it may indicate the arrival of a delay outburst.

\section{Data Availability}

The data of this study are from Jiangxi University of Science and Technology and Chongqing University.

\section{Conflicts of Interest}

The authors declare no conflicts of interest.

\section{Acknowledgments}

This work was supported by the National Natural Science Foundation of China (no. 52064016), Jiangxi Science and Technology Research Project Fund (Youth) (GJJ190485), Doctoral Research Foundation of Jiangxi University of Science and Technology (no. 205200100213), Discipline Construction Fund of Emergency Management Institute (204203700032), and Jiangxi Provincial Thousand Talents Plan Project (jxsq2018102092, 205201000029). The authors wish to acknowledge these supports.

\section{References}

[1] B. Zhao, "Analysis of delayed coal and gas outburst and its prevention measures," Hunan safety and disaster prevention, vol. 6, no. 157, pp. 44-45, 2008. 
[2] B. Lin, F. Yan, C. Zhu et al., "Cross-borehole hydraulic slotting technique for preventing and controlling coal and gas outbursts during coal roadway excavation," Journal of Natural Gas Science and Engineering, vol. 26, pp. 518-525, 2015.

[3] F. Yan, B. Lin, C. Zhu et al., "A novel ECBM extraction technology based on the integration of hydraulic slotting and hydraulic fracturing," Journal of Natural Gas Science and Engineering, vol. 22, pp. 571-579, 2015.

[4] J. Xu, D. Liu, S. J. Peng et al., "Coal and gas outburst analogous test under the different diameter of exposed coal seam surface," Journal of China Coal Society, vol. 38, no. 1, pp. 09-14, 2013.

[5] J. Xu, Y. Q. Tao, G. Z. Yin et al., "Development and application of coal and gas outburst simulation test device," Chinese Journal of Rock Mechanics and Engineering, vol. 27, no. 11, pp. 2354-2362, 2008.

[6] S. J. Peng, W. J. Yang, B. Zhou et al., "Study on the evolution law of gas pressure in the process of coal and gas outburst under true triaxial stresses," Chinese Journal of Rock Mechanics and Engineering, vol. 39, no. 09, pp. 39-49, 2020.

[7] C. L. Jiang and L. W. Guo, "Mechanism and simulation test of delayed outburst," Journal of China Coal Society, vol. 24, no. 4, pp. 373-378, 1999.

[8] X. R. Luo, N. N. Xia, and Z. Z. Jia, "Research on Stress Simulation and Mechanism of Delaying Coal and Gas Outburst in Coal Driving," Journal of China university of mining and technology, vol. 35, no. 5, pp. 571-575, 2006.

[9] F. Nie, H. Wang, and L. Qiu, "Research on the disaster-inducing mechanism of coal-gas outburst," Advances in Civil Engineering, vol. 2020, pp. 1-12, 2020.

[10] Z. J. Bao, "Examples and analysis of delayed outburst of coal and gas," Coal engineer, vol. 6, pp. 49-56, 1992.

[11] L. H. Xu, H. N. Jiang, and Z. C. Feng, "Effect analysis of barrier layer thickness on outburst delay time based on combination model," Safety In Coal Mines, vol. 7, pp. 9-13, 2018.

[12] X. Q. Li, G. Z. Yin, B. Cai et al., "Simulation and analysis of mechanics of coal and gas delay outburst," Journal of Chongqing University, vol. 34, no. 4, pp. 13-19, 2011.

[13] J. Xu, W. J. Zhou, D. Liu et al., "Temperature and acoustic emission characteristics of coal in the process of outburst under the influence of mining," Journal of China Coal Society, vol. 38, no. 2, pp. 239-244, 2013.

[14] C. Wang, J. Xie, and J. Liu, "Deformation and acoustic emission characteristics of cracked granite during creep," Advances in Materials Science and Engineering, vol. 2020, pp. 1-11, 2020.

[15] T. Ai, R. Zhang, J. F. Liu et al., "Space-time evolution rules of acoustic emission locations under triaxial compression," Journal of China Coal Society, vol. 36, no. 12, pp. 2048-2057, 2011.

[16] G. Z. Yin, X. Q. Li, C. B. Jiang et al., "Simulation experiments of coal and gas delay outburst in rock cross-cut coal uncovering," Journal of University of Science and Technology Beijing, vol. 32, no. 7, pp. 827-832, 2010.

[17] X. P. Li, B. Wang, and G. L. Zhou, "Research on distribution rule of geostress in deep stratum Chinese mainland," Chinese Journal of Rock Mechanics and Engineering, vol. 31, pp. 2875-2880, 2012.

[18] C. B. Lian and W. Li, "Exploration on the enhance of gas pressure prediction accuracies in coal seam," Journal of Henan Polytechnic University (Natural Science), vol. 27, no. 2, pp. 12-20, 2008.

[19] M. B. Wold, L. D. Connell, and S. K. Choi, "The role of spatial variability in coal seam parameters on gas outburst behaviour during coal mining," International Journal of Coal Geology, vol. 75, no. 1, pp. 1-14, 2009.

[20] S. Xue, Y. C. Wang, J. Xie et al., "A coupled approach to simulate initiation of outbursts of coal and gas - model development," International Journal of Coal Geology, vol. 86, no. 2-3, pp. 222-230, 2011.

[21] Z. J. Zhou and R. S. Yang, "Studies of engineering properties of compaction loses," Journal of Ningxia University, vol. 28, no. 3, pp. 241-244, 2007.

[22] Y. Zhang, H. He, Z. Y. Zeng et al., "Comparison of strength characteristics of fly ash-lime Improved loess and compacted loess," Science Technology and Engineering, vol. 21, no. 8, pp. 3265-3273, 2021.

[23] X. S. Li, K. Peng, J. Peng et al., "Effect of thermal damage on mechanical behavior of a fine-grained sandstone," Arabian Journal of Geosciences, vol. 14, Article ID 1212, 2021.

[24] E. Y. Wang, Z. H. Li, D. X. Li et al., "Application of electromagnetic radiation monitoring equipment in monitoring and warning of coal and gas outburst," Safety In Coal Mines, vol. 51, no. 10, pp. 46-51, 2020.

[25] J. P. Tang, N. Hao, Y. S. Pan et al., "Experimental study on precursor characteristics of coal and gas outburst based on acoustic emission energy analysis," Chinese Journal of Rock Mechanics and Engineering, vol. 40, no. 1, pp. 31-42, 2021. 